\title{
Heat and mass transfer modelling of continuous Wurster spray granulation with external product classification
}

\author{
Müller, D. ${ }^{\text {a*}}$; Bück, A. ${ }^{\text {a,b}}$; Tsotsas, E. ${ }^{\text {a }}$ \\ ${ }^{a}$ Department of Thermal Process Engineering. Otto von Guericke University, Magdeburg, Germany \\ ${ }^{\mathrm{b}}$ Institute of Particle Technology. FAU Erlangen-Nuremberg, Erlangen, Germany. \\ *E-mail of the corresponding author: daniel.mueller@ovgu.de
}

\begin{abstract}
Wurster granulation with external product classification can be used for stable continuous coating or layering processes. It has been ascertained from recent population balance simulations that the ratio of the spray rate to the nuclei feed rate can be used to control the thickness of the sprayed product layer. However, thermal conditions are not considered by population balances regarding the particle size as distributed property. For this reason, heat and mass transfer is investigated in the present contribution by modelling of several subprocesses. The results can be used to discuss the cause of fluidized bed destabilization due to over-wetting.
\end{abstract}

Keywords: continuous operation; Wurster fluidized bed; spray granulation; spray limits; heat and mass transfer. 


\section{Introduction}

The continuous Wurster spray granulation with external product classification is suitable for particle growth processes such as coating and layering with constant product specifications (size, layer or porosity distribution) and product yields. As ascertained by recent results and from former studies [1], higher spray rates and lower feed rate are needed to achieve larger layer thicknesses. Thereby the spray rate is limited by thermal conditions, fluidization gas saturation, drying kinetic and agglomeration tendency which might lead to process instability due to over-wetting. For this reason it is aimed in this contribution to describe the heat and mass transfer of the Wurster-granulator by diverse models, to determine spray limits and to discuss the cause of process destabilization.

\section{Process configuration and modelling}

The present contribution bases on a former case study of Hampel [1] describing the here discussed process with a two-zone population balance model whose simulated product size distributions has been validated by lab scale experiments for a certain range of process parameters. The heat and mass transfer of this Wurster granulation process should be investigated with several model approaches such as an ideal two-component particle growth model, steady state particle circulation in Wurster-chamber, pneumatic transport and spray deposition in Wurster-tube (spray zone denoted with $\alpha$ ) as well as drying and heating outside the Wurster tube (drying zone denoted with 1- $\alpha$ ).

\subsection{Reference case - Experimental design and modelling}

The experimental design of the continuous Wurster spray granulation in Hampel's investigations [1] consists of a conical fluidized bed apparatus which is interconnected to a straight-duct air classifier as illustrated in Fig. 1a). Particles are raised through the Wurstertube due to high gas velocities and are sprayed with a solid-containing liquid. Above the Wurster-tube particles fall back into the drying zone. The particle circulation has been described, e.g. by Börner et al. [2]:

$$
\tau_{1-\alpha}=\tau_{\alpha} \frac{1-\alpha}{\alpha},
$$

wherein $\tau_{\alpha}$ and $\tau_{1-\alpha}$ represent the residence time (s) of the spray zone and the drying zone, respectively. Further, $\alpha$ is defined as the volume fraction $\left(\mathrm{m}^{3} / \mathrm{m}^{3}\right)$ of spray zone related to the total volume of the disperse system (spray zone and drying zone). 


\subsection{Heat and mass transfer modelling}

The heat and mass model is illustrated in Fig. 1b) and assumes basically the following aspects. Particles circulate through spray and drying zone with constant residence times. The interior of Wurster-tube is seen as spray zone and the drying zone is assumed as a homogeneous fluidized bed describing the outer region of the Wurster-tube. Stationary pneumatic transport and moistening of particles takes place in the spray zone, wherein swarm sinking is also considered. The temperature of the particles leaving the spray zone is assumed to be the wet bulb temperature. Finally, evaporation of sprayed water content (drying period) and particle heating (heating period) occur in the drying zone until the particles re-enter the spray zone.

a)

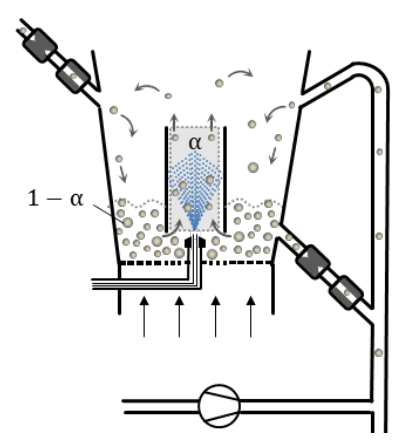

b)

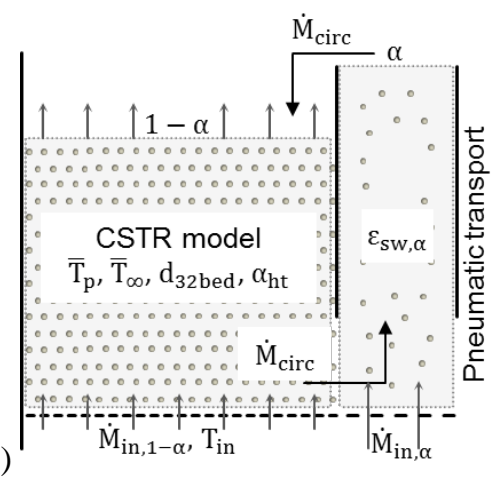

Fig. 1 a) Wurster spray granulation chamber with an interconnected straight-duct air classifier [1], b) Two-zone heat and mass transfer model.

Furthermore, a simplified two-component particle growth model is used in order to approximate the stationary size distribution of fluidized bed particles. This model contains several assumptions such as: mono-sized feed and product, mono-shaped disperse system of solid spheres, constant feed and spray rate, evenly distributed particle growth rate, nondistributed residence time due to permanent classifying with an ideal separation performance and steady state conditions. As a conclusion, a two-component single particle model consisting of a spherical core and a spherical layer with a well-defined core diameter and coating layer thickness can be derived. The number density distribution regarding the size of the fluidized bed particles turns out to be a uniform distribution. Hence, the Sauter diameter $\mathrm{d}_{32 \text {,bed }}$ and an average effective particle density $\bar{\rho}_{\mathrm{p} \text {,eff }}$ among the population can be obtained analytically which are both needed for the description of heat and mass transfer. 


\subsubsection{Pneumatic transport in spray zone}

The residence time in the spray zone is a parameter which is required for the two-zone population balance of the abovementioned reference case. The spray zone residence time is approached in this contribution based on the assumption of stationary pneumatic transport with constant solid volume fraction:

$$
\tau_{\alpha}=\frac{L_{w t}}{u_{g, \alpha} / \varepsilon_{s w, \alpha}-k_{s w} u_{s}\left(d_{32, b e d)}\right.} \text { and } k_{s w}=\left(1-\varepsilon_{s w, \alpha}\right)^{5,5(A r)^{-0,06}} \cdot \quad \text { (2a) and (2b) }
$$

Eq. 2a takes into account the Wurster-tube length $L_{w t}(m)$, the spray zone gas velocity $u_{g, \alpha}$ $(\mathrm{m} / \mathrm{s})$ and the solid volume fraction in spray zone $\varepsilon_{\mathrm{sw}, \alpha}\left(\mathrm{m}^{3} / \mathrm{m}^{3}\right)$ which can be estimated by CFD-DEM simulations. Further Eq. 2a includes the swarm sinking correction $\mathrm{k}_{\mathrm{sw}}(-)$ and the terminal sinking velocity $\mathrm{u}_{\mathrm{s}}(\mathrm{m} / \mathrm{s})$ of a single sphere. The swarm sinking factor $\mathrm{k}_{\mathrm{sw}}$ can be calculated with Eq. 2b suggested by Richardson and Zaki [3].

\subsubsection{Fluidization gas cooling, particle drying and particle heating in drying zone}

The fluidization gas cooling is depicted schematically in Fig. 2a). Fig. 2b) shows the drying period and the heating period of a single particle with retention time $t_{1-\alpha}(s)$ in the drying zone.

a)

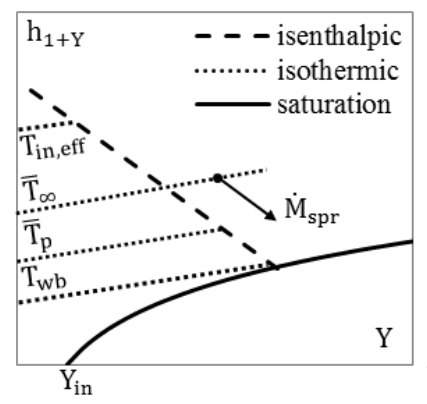

b) 0

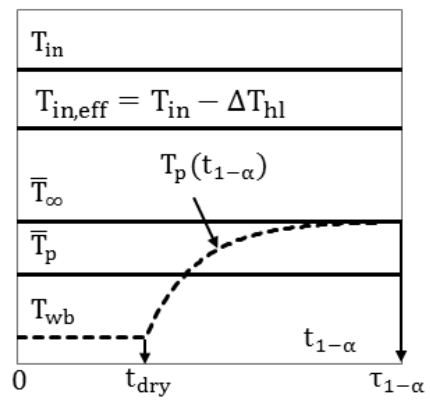

Fig. 2 a) Schematic Mollier-diagram illustrating the temperature range inside the Wurstergranulator, b) Single particle temperature evolution versus retention time in the drying zone.

The average gas temperature $\overline{\mathrm{T}}_{\infty}\left({ }^{\circ} \mathrm{C}\right)$ in the drying zone is calculated with incoming gas temperature $\mathrm{T}_{\text {in }}\left({ }^{\circ} \mathrm{C}\right)$ below the distributor plate, with the temperature drop $\Delta \mathrm{T}_{\mathrm{hl}}\left({ }^{\circ} \mathrm{C}\right)$ due to heat losses at the gas distributer plate, the solid content of spray solution $\mathrm{x}_{\mathrm{s}}(\mathrm{kg} / \mathrm{kg})$, with the evaporation energy $\Delta \mathrm{h}_{\mathrm{eva}}{ }^{\circ}(\mathrm{J} / \mathrm{kg})$ of deposited spray solvent and others: 


$$
\bar{T}_{\infty}=T_{i n}-\Delta T_{h l}-\frac{\left(\dot{M}_{s p r}\left(1-x_{S}\right)-\dot{M}_{i n, \alpha} \frac{\varphi_{\alpha} Y_{s a t}\left(T_{i n}, Y_{i n}\right)}{1+Y_{i n}}\right) \Delta h_{e v a^{\circ}\left(T_{w b}\right)}}{\dot{M}_{i n, 1-\alpha} c_{p, f l}}
$$

Particles, leaving the spray zone and entering the drying zone, have been cooled down to the wet bulb temperature. The particle temperature evolution in the drying zone is divided into two segments: the drying period as first segment and the heating period as second segment. The time interval of 0 to the required drying time $t_{\text {dry }}$ defines the drying period. Within the drying period, the particle temperature $T_{p}$ remains at the wet bulb temperature $T_{w b}$. The heating period starts directly after complete evaporation of coating humidity where the particle temperature is still at the wet bulb temperature. The particle temperature rises subsequently and approaches the average surrounding temperature of the fluidization gas $\overline{\mathrm{T}}_{\infty}$ with increasing drying zone retention time. Finally the particles enter the spray zone at the total residence time $\tau_{1-\alpha}$. in the drying zone. The particle temperature curve of the heating period is obtained from the energy balance of a single particle:

$$
T_{p}=\bar{T}_{\infty}-\left(\bar{T}_{\infty}-T_{w b}\right) \exp \left(-S t^{\prime}\left(t_{1-\alpha}-t_{d r y}\right)\right) .
$$

The particle heating kinetic is represented by the modified Stanton number $\mathrm{St}^{\prime}(1 / \mathrm{s})$ which is defined with $\mathrm{St}^{\prime}=6 \alpha_{\mathrm{ht}} /\left(\mathrm{d}_{32 \text {,bed }} \bar{\rho}_{\mathrm{p} \text {,eff }} \mathrm{c}_{\mathrm{p}}\right)$ and the heat transfer coefficient $\alpha_{\mathrm{ht}}\left(\mathrm{W} / \mathrm{m}^{2} / \mathrm{K}\right)$ can be determined with Gnielinski's approach [4]. The drying time is approximated by an energy balance assuming constant drying rate. In order to estimate the average particle temperature $\overline{\mathrm{T}}_{\mathrm{p}}$ in the drying zone, the time function of the particle temperature (Eq. 4) has been integrated with retention time $t_{1-\alpha}$ and devided by the total residence time in drying zone $\tau_{1-\alpha}$ :

$$
\begin{aligned}
& \bar{T}_{p}=T_{w b} \frac{t_{d r y}}{\tau_{1-\alpha}}+\bar{T}_{\infty}\left(1-\frac{t_{d r y}}{\tau_{1-\alpha}}\right)-\left(\bar{T}_{\infty}-T_{w b}\right) k_{h t} \\
& k_{h t}=\frac{\left.1-e^{-S t^{\prime}\left(\tau_{1-\alpha}-t\right.} d r y\right)}{s t^{\prime} \tau_{1-\alpha}} .
\end{aligned}
$$

Thereby $\mathrm{k}_{\mathrm{ht}}$ is introduced as a coefficient of heating kinetic including the influence of the modified Stanton number on the average particle temperature.

\subsection{Parameter setting}

The parameter values of the material properties, mass flow and inlet temperature of the fluidization gas as well as the bed mass are chosen according to the reference case [1] and are listed in Table 1. Therein are also given further parameters which are the swarm solid volume fraction $\varepsilon_{\mathrm{sw}, \alpha}$ and the relative air humidity $\varphi_{\alpha}$ in the spray zone. Both parameters are adapted to measured fluidized bed temperature. Beside this, a heat loss temperature difference $\Delta \mathrm{T}_{\mathrm{hl}}$ has been determined from measurements determining the temperature below and above the distributor plate. 
Table 1. Model parameters

\begin{tabular}{|c|c|c|c|c|c|c|c|c|c|c|}
\hline $\begin{array}{c}\mathbf{d}_{\mathrm{f}} \\
\mathbf{m m}\end{array}$ & $\begin{array}{c}d_{p r} \\
\mathbf{m m}\end{array}$ & $\begin{array}{c}\rho_{\mathrm{f}, \mathrm{eff}} \\
\frac{\mathbf{k g}}{\mathbf{m}^{3}}\end{array}$ & $\begin{array}{c}\rho_{c, \text { eff }} \\
\frac{\mathbf{k g}}{\mathbf{m}^{3}}\end{array}$ & $\begin{array}{l}\dot{\mathbf{M}}_{\text {in }} \\
\frac{\text { kg }}{\mathbf{h}}\end{array}$ & $\begin{array}{l}x_{s} \\
\mathbf{k g} \\
\mathbf{k g}\end{array}$ & $\begin{array}{l}\mathbf{T}_{\text {in }} \\
{ }^{\circ} \mathbf{C}\end{array}$ & $\begin{array}{c}M_{\text {bed }} \\
\text { kg }\end{array}$ & $\begin{array}{l}\boldsymbol{\varepsilon}_{\mathbf{s w}, \boldsymbol{\alpha}} \\
\frac{\mathbf{m}^{3}}{\mathbf{m}^{3}}\end{array}$ & $\begin{array}{c}\boldsymbol{\varphi}_{\alpha} \\
-\end{array}$ & $\begin{array}{c}\Delta \mathbf{T}_{\mathbf{h l}} \\
\mathbf{K}\end{array}$ \\
\hline 0.3 & 0.4 & 1380 & 806 & 70 & 0.32 & 70 & 1 & 0.02 & 0.35 & 5.7 \\
\hline
\end{tabular}

In the present contribution, model results based on Table 1 and three different spray rates $(0.8 \mathrm{~kg} / \mathrm{h}, 1.1 \mathrm{~kg} / \mathrm{h}$ and $1.3 \mathrm{~kg} / \mathrm{h})$ are investigated.

\section{Results and Discussion}

Several spray rate independent parameters of the Wurster granulation can be obtained from the presented the heat and mass transfer model, see in Table 2. These include the Sauter diameter of the bed particles $d_{32 \text {,bed }}$, the swarm correction factor $k_{s w}$, the single particle sinking velocity $\mathrm{u}_{\mathrm{s}}$, the superficial gas velocity in spray zone $\mathrm{u}_{\mathrm{g}, \alpha}$ as well as the residence time in spray zone $\tau_{\alpha}$ and drying zone $\tau_{1-\alpha}$. It can be seen that the swarm effect can not be neglected with a factor 0.93 . The sinking velocity is smaller than the spray zone gas velocity which is a requirement for stable circulation in the Wurster-granulator. The spray zone residene time is much lower than the drying zone residence time.

The drying time $t_{d r y}$, the heat transfer coefficient $\alpha_{\mathrm{ht}}$, the modified Stanton number $\mathrm{St}^{\prime}$, the heating kinetic factor $\mathrm{k}_{\mathrm{ht}}$, the average gas temperature $\overline{\mathrm{T}}_{\infty}$ and the average particle temperature $\overline{\mathrm{T}}_{\mathrm{p}}$ are calculated for three different spray rates $\dot{\mathrm{M}}_{\text {spr }}$, respectively (see Table 3). The drying time increases linearly with spray rate and it is negligibly small compared to the residence time in the drying zone. The low drying time is caused by the high heat and mass transfer conditions of the fluidized bed. The particle heating coefficient is small. Thus the contribution of the particle heating kinetic to the average particle temperature can be neglected. Hence, the average particle temperature hardly differs from the average gas temperature in the drying zone due to the low drying times and the low particle heating kinetic coefficients.

Table 2. Spray rate independent model results

\begin{tabular}{cccccc}
\hline $\begin{array}{c}\mathbf{d}_{\mathbf{3 2 , \text { bed }}} \\
\mathbf{m m}\end{array}$ & $\mathbf{k}_{\mathbf{s w}}$ & $\mathbf{u}_{\mathbf{s}}$ & $\mathbf{u}_{\mathbf{g}, \boldsymbol{\alpha}}$ & $\boldsymbol{\tau}_{\boldsymbol{\alpha}}$ & $\boldsymbol{\tau}_{\mathbf{1}-\boldsymbol{\alpha}}$ \\
\hline 0.35 & - & $\mathbf{m} / \mathbf{s}$ & $\mathbf{m} / \mathbf{s}$ & $\mathbf{s}$ & $\mathbf{s}$ \\
\hline
\end{tabular}


Table 3. Spray rate dependent model results

\begin{tabular}{|c|c|c|c|c|c|c|}
\hline$\dot{\mathbf{M}}_{\text {spr }}$ & $t_{\text {dry }}$ & $\alpha_{\mathrm{ht}}$ & $\mathbf{S t}^{\prime}$ & $\mathbf{k}_{\mathbf{h t}}$ & $\overline{\mathbf{T}}_{\infty}$ & $\overline{\mathbf{T}}_{\mathbf{p}}$ \\
\hline$\frac{\mathrm{kg}}{\mathrm{h}}$ & $\mathbf{s}$ & $\frac{w}{m K}$ & $1 / \mathrm{s}$ & $\%$ & ${ }^{\circ} \mathbf{C}$ & ${ }^{\circ} \mathrm{C}$ \\
\hline 0.8 & 0.018 & 503.6 & 3.19 & 1.234 & 43.30 & 43.06 \\
\hline 1.1 & 0.027 & 506.7 & 3.21 & 1.226 & 31.77 & 31.67 \\
\hline 1.3 & 0.034 & 509.0 & 3.22 & 1.221 & 24.29 & 24.08 \\
\hline
\end{tabular}

The model results of the spray rate of $0.8 \mathrm{~kg} / \mathrm{h}$ are compared with the measured fluidized bed temperature of a Wurster batch granulation process spraying a solution with $32 \mathrm{wt}-\%$ sodium bencoate solution on MCC-particles.

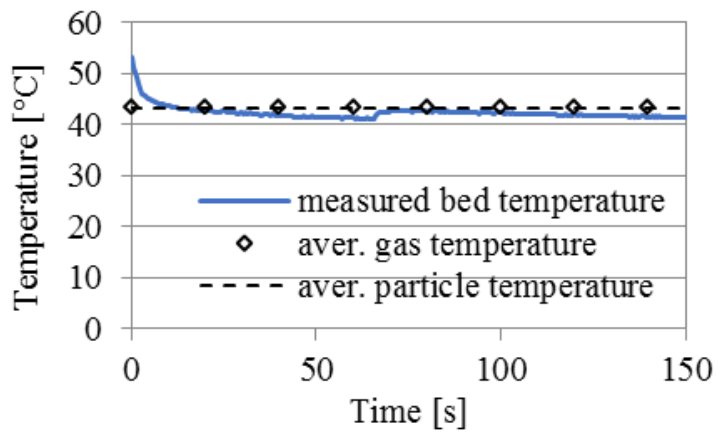

Fig. 3 Model-based average gas and average particle temperature adapted to measured fluidized bed temperature.

Additionally, several batch processes spraying pure water have been conducted for different bed masses $(0.5 \mathrm{~kg}, 1 \mathrm{~kg}, 1.5 \mathrm{~kg}$, and $2 \mathrm{~kg})$ and different fluidization gas temperatures $\left(70^{\circ} \mathrm{C}\right.$, $80^{\circ} \mathrm{C}$ and $90^{\circ} \mathrm{C}$ ). Thereby the spray rate has been increased until destabilization of the fluidized bed took place.

\section{Conclusions}

Although the drying kinetic in the drying zone is ascertained as large, process destabilization due to over-wetting takes place far below the point of saturation. For this reason, it is presumed that the enhancement of agglomeration tendency with the larger spray rates cause the destabilization. Agglomerated particles might not be raised through the Wurster-tube for the reason that the sinking velocity is strongly increased. Hence agglomerates accumulate at the bottom of the fluidized bed, block the particle circulation and finally destabilize the fluidization. 


\section{Nomenclature}

$\begin{array}{lll}\text { Ar } & \text { Archimedes number } & - \\ \mathrm{C} & \text { heat capacity } & \mathrm{Jkg}^{-1} \mathrm{~K}^{-1} \\ \dot{\mathrm{M}} & \text { mass flow } & \mathrm{kgs}^{-1} \\ \mathrm{Y} & \text { air moisture load content } & \mathrm{kgkg}^{-1}\end{array}$

Greek letters

$\varphi \quad$ relative moist of air

Subscripts

$\begin{array}{ll}\text { c } & \text { dried coating material } \\ \text { eff } & \text { effective } \\ \text { in } & \text { inlet fluidization gas } \\ \text { sat } & \text { saturation }\end{array}$

\section{References}

[1] Hampel, N. Bück, A. Peglow, M. Tsotsas, E. Continuous Pellet Coating in a Wurster Fluidized Bed Process, Chemical Engineering Science 2013, 86, 87-98.

[2] Börner, M.; Peglow, M.; Tsotsas, E. Derivation of parameters for a two compartment population balance model of Wurster fluidized bed granulation. Powder Technology 238 (2012), 122-131.

[3] Richardson, J. F., Zaki, W. N. Trans. Inst. Chem. Engrs. 1954, 32, 35-53.

[4] Gnielinski, V. Wärme- und Stoffübertragung in Festbetten, Chem.-Ing.-Tech. 1980, 52, 228-236. 